\title{
Illustrated treatment of refractory immune thrombotic thrombocytopenic purpura with caplacizumab
}

\author{
Brandon Tse (1) ,' Megan Buchholz, ${ }^{2}$ Katerina Pavenski ${ }^{3,4}$
}

${ }^{1}$ Temerty Faculty of Medicine, University of Toronto, Toronto, Ontario, Canada

${ }^{2}$ Apheresis Unit, St Michael's Hospital, Toronto, Ontario, Canada

${ }^{3}$ Departments of Laboratory Medicine and Medicine, St Michael's Hospital- Unity Health Toronto, Toronto, Ontario, Canada

${ }^{4}$ Departments of Laboratory Medicine and Pathobiology, University of Toronto, Toronto, Ontario, Canada

\section{Correspondence to} Dr Katerina Pavenski; katerina.pavenski@unityhealth. to

Accepted 20 July 2021

\section{DESCRIPTION}

A 58-year-old woman was hospitalised with a relapse of thrombotic thrombocytopenic purpura (TTP). She was diagnosed with immune TTP 10 years ago and has had two previous relapses. Her first episode was treated with therapeutic plasma exchange (TPE) and high-dose steroids; two relapses, which occurred 3 years apart, were also additionally treated with rituximab. Rituximab treatment during the second relapse was discontinued early due to anaphylactic reaction to the third infusion. Previous acute complications of TTP included non-ST-elevation myocardial infarction. Following the last episode, the patient had persistent ADAMTS13 deficiency (activity less than 5\%), but declined further immunosuppressive treatment.

On admission, she had altered level of consciousness and required intubation. Admission bloodwork (day 1) revealed a platelet count of $7 \times 10^{9} / \mathrm{L}$, haemoglobin $110 \mathrm{~g} / \mathrm{L}$, lactate dehydrogenase $2558 \mathrm{U} / \mathrm{L}$ (ULN $195 \mathrm{U} / \mathrm{L}$ ), haptoglobin $0.03 \mathrm{~g} / \mathrm{L}$ (normal $0.30-2.00 \mathrm{~g} / \mathrm{L}$ ) and indirect bilirubin $59 \mu \mathrm{mol} / \mathrm{L}$ (ULN $12 \mu \mathrm{mol} / \mathrm{L}$ ). Blood film showed RBC fragmentation and ADAMTS13 activity was less than $1 \%$. She had evidence of acute kidney injury (admission creatinine 192 U/L, ULN $102 \mathrm{U} / \mathrm{L}$, baseline creatinine $51 \mathrm{U} / \mathrm{L}$ ) and cardiac ischaemia (troponin $2.643 \mu \mathrm{g} / \mathrm{L}$, ULN $0.4 \mu \mathrm{g} / \mathrm{L}$ ). CT of the head did not reveal any acute pathology. TPE was initiated with solvent-detergent treated plasma and continued daily. The patient also received methylprednisolone $1 \mathrm{~g}$ daily for 3 days, followed by highdose steroids. Rituximab treatment (4 weekly doses of $375 \mathrm{mg} / \mathrm{m}^{2}$ ) was delayed due to concerns about anaphylaxis, but eventually was administered on day 7 , with desensitisation protocol. She tolerated

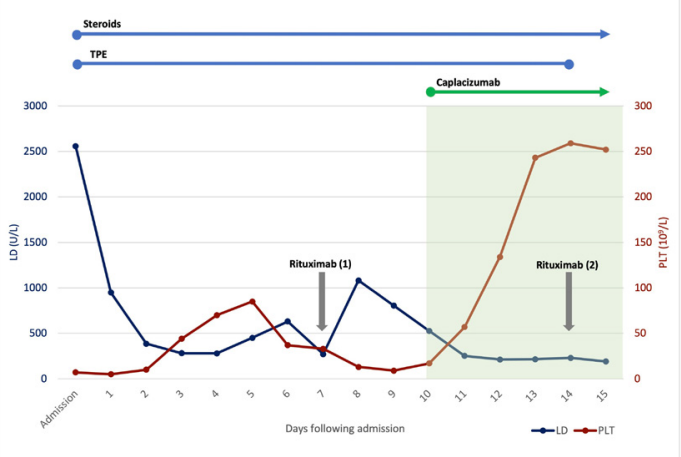

Figure 1 Lactate dehydrogenase and platelet count over the course of patient's admission with treatments shown. LD, lactate dehydrogenase; PLT, platelets; TPE, plasma exchange.

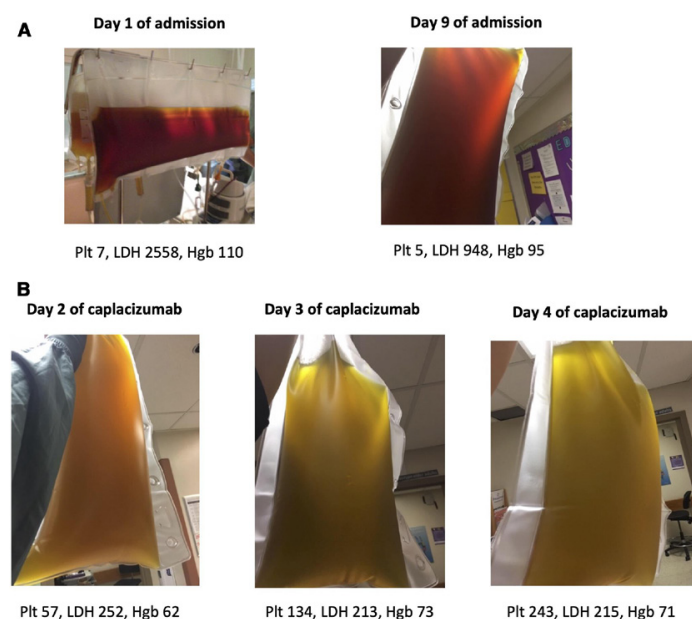

Figure 2 Photographs of patient's plasma before (A) and after (B) caplacizumab treatment. Plt, platelets $\left(10^{9} / \mathrm{L}\right) ; \mathrm{LDH}$, lactate dehydrogenase $(\mathrm{U} / \mathrm{L}) ; \mathrm{Hgb}$, haemoglobin $(\mathrm{g} / \mathrm{L})$.

rituximab but had no improvement clinically. There was also no improvement in her counts, haemolytic or organ damage markers (figure 1). Photographs of patient plasma on day 1 and 9 are shown in figure $2 \mathrm{~A}$, demonstrating significant haemoglobinaemia. Caplacizumab was requested through a compassionate access programme. The patient commenced caplacizumab $1 \mathrm{mg}$ on day 10 , using Caplacizumab Treatment for Acquired Thrombotic Thrombocytopenic Purpura (HERCULES) trial dosing protocol. ${ }^{1}$ Over the next few days, platelet count and lactate dehydrogenase improved dramatically (figures 1 and 2) and so did haemoglobinaemia (see figure $2 \mathrm{~B}$ ). The patient's clinical condition also improved; she was extubated and discharged from

\section{Patient's perspective}

To have patience, faith and a caring doctor that did not give up on me and got me caplacuzimab that saved my life, gave hope for the future.

\section{Learning points}

- Caplacizumab has been studied as initial therapy, but can also be rapidly effective in refractory TTP cases.

- Caplacizumab had an acceptable safety profile with no bleeding complications in this critically ill patient. 
intensive care unit on day 15 of admission (day 6 of caplacizumab). TPE was discontinued on day 15 (after 15 exchanges), and the patient was discharged home on day 17. Her renal function has normalised, and she did not have any permanent neurological deficits. There were no bleeding complications. The patient received her third and fourth doses of rituximab and completed a steroid taper as an outpatient. During steroid taper, she developed a local allergic reaction at the site of caplacizumab injections. As she was in clinical remission, doing well and eager to stop therapy, a decision was made to discontinue caplacizumab (after 65 days of therapy) and monitor her laboratory tests frequently. Her ADAMTS13 activity remained severely deficient, but she declined any further immunosuppression and to date has not relapsed.

This case report illustrates clinical and laboratory evolution of a patient with TTP refractory to standard of care therapies following addition of caplacizumab, adding to the few existing reports in the literature. ${ }^{2-4}$

Correction notice This article has been corrected since published online first. The Competing Interest statement has been updated.

Twitter Brandon Tse @BrandonTse3
Contributors $\mathrm{BT}, \mathrm{MB}$ and $\mathrm{KP}$ contributed to the acquisition and interpretation of data, writing the case report and review of the manuscript for publication. MB and KP managed the patient and contributed to the conception of the case report.

Funding The authors have not declared a specific grant for this research from any funding agency in the public, commercial or not-for-profit sectors.

Competing interests KP declares honoraria for consulting and speaking from Ablynx/Sanofi and Shire/Takeda, participation in industry sponsored trials by Ablynx/ Sanofi and Shire/Takeda.

Patient consent for publication Obtained.

Provenance and peer review Not commissioned; externally peer reviewed.

ORCID iD

Brandon Tse http://orcid.org/0000-0003-1994-8662

\section{REFERENCES}

1 Scully M, Cataland SR, Peyvandi F, et al. Caplacizumab treatment for acquired thrombotic thrombocytopenic purpura. N Engl J Med Overseas Ed 2019;380:335-46.

2 Belani N, Barrios-Anderson A, Rafelson W, et al. Caplacizumab as step-up therapy in refractory TTP utilizing ADAMTS-13 activity and evidence of end-organ damage. Blood 2019;134:4909.

3 Khan S, Landry K, Umyarova E. Caplacizumab treatment for acquired refractory thrombotic thrombocytopenic purpura. Br J Haematol 2020;191:e44-6.

4 Mellaza C, Henry N, Fayolle P-M, et al. Refractory auto-immune thrombotic thrombocytopenic Pupura successfully treated with Caplacizumab. Front Med $2020 ; 7: 549931$

Copyright 2021 BMJ Publishing Group. All rights reserved. For permission to reuse any of this content visit

https://www.bmj.com/company/products-services/rights-and-licensing/permissions/

BMJ Case Report Fellows may re-use this article for personal use and teaching without any further permission.

Become a Fellow of BMJ Case Reports today and you can:

- Submit as many cases as you like

- Enjoy fast sympathetic peer review and rapid publication of accepted articles

- Access all the published articles

Re-use any of the published material for personal use and teaching without further permission

Customer Service

If you have any further queries about your subscription, please contact our customer services team on +44 (0) 2071111105 or via email at support@bmj.com.

Visit casereports.bmj.com for more articles like this and to become a Fellow 